\title{
Seasonal Dynamics of Bathyarchaeota-Dominated Benthic Archaeal Communities Associated with Seagrass (Zostera japonica) Meadows
}

\author{
Pengyuan Liu ${ }^{1,2} \mathbb{D}^{-}$, Haikun Zhang ${ }^{1,3} \mathbb{D}^{-}$, Zenglei Song ${ }^{1,2}$, Yanyan Huang ${ }^{1,2}$ and Xiaoke Hu ${ }^{1,2,3, *}$ \\ 1 Key Laboratory of Coastal Biology and Bioresource Utilization, Yantai Institute of Coastal Zone Research, \\ Chinese Academy of Sciences, Yantai 264003, China; pyliu@yic.ac.cn (P.L.); hkzhang@yic.ac.cn (H.Z.); \\ zlsong@yic.ac.cn (Z.S.); yyhuang@yic.ac.cn (Y.H.) \\ 2 University of Chinese Academy of Sciences, Beijing 100049, China \\ 3 Laboratory for Marine Biology and Biotechnology, \\ Qingdao National Laboratory for Marine Science and Technology, Qingdao 266237, China \\ * Correspondence: xkhu@yic.ac.cn
}

Citation: Liu, P.; Zhang, H.; Song, Z.; Huang, Y.; Hu, X. Seasonal Dynamics of Bathyarchaeota-Dominated Benthic Archaeal Communities Associated with Seagrass (Zostera japonica) Meadows. J. Mar. Sci. Eng. 2021, 9 , 1304. https://doi.org/10.3390/ jmse9111304

Received: 6 October 2021

Accepted: 17 November 2021

Published: 21 November 2021

Publisher's Note: MDPI stays neutral with regard to jurisdictional claims in published maps and institutional affiliations.

Copyright: () 2021 by the authors. Licensee MDPI, Basel, Switzerland. This article is an open access article distributed under the terms and conditions of the Creative Commons Attribution (CC BY) license (https:// creativecommons.org/licenses/by/ $4.0 /)$.

\begin{abstract}
Little is known about the seasonal dynamic of archaeal communities and their potential ecological functions in temperate seagrass ecosystems. In this study, seasonal changes in diversity, community structure, and potential metabolic functions of benthic archaea in surface sediments of two seagrass meadows along the northern Bohai Sea in China were investigated using Miseq sequencing of the 16S rRNA gene and Tax4Fun2 functional prediction. Overall, Crenarchaeota (mainly Bathy-15, Bathy-8, and Bathy-6) dominated, followed by Thermoplasmatota, Asgardarchaeota, and Halobacterota, in terms of alpha diversities and relative abundance. Significant seasonal changes in the entire archaeal community structure were observed. The major phyla Methanobacteria, Nitrosopumilales, and genus Methanolobus had higher proportions in spring, while MBG-D and Bathyarchaeota were more abundant in summer and autumn, respectively. Alpha diversities (Shannon and Simpson) were the highest in summer and the lowest in autumn (ANOVA test, $p<0.05$ ). Salinity, total organic carbon, and total organic nitrogen were the most significant factors influencing the entire archaeal community. Higher cellulose and hemicellulose degradation potentials occurred in summer, while methane metabolism potentials were higher in winter. This study indicated that season had strong effects in modulating benthic archaeal diversity and functional potentials in the temperate seagrass ecosystems.
\end{abstract}

Keywords: archaea; seasonality; diversity; ecological functions; seagrass; Bathyarchaeota

\section{Introduction}

Seagrass is a globally distributed submerged marine angiosperm and plays a key role in building the coastal ecology that forms a crucial ecotone between marine and terrestrial environments. Seagrass provides numerous important ecological services [1,2], including carbon sequestration [3], shoreline protection from erosion [4], and providing habitats, nurseries, and food for fish and invertebrates [5-8]. As one of the most productive ecosystems in the world, seagrass meadows benefit from the high turnover rates of organic matter $(\mathrm{OM})$ and biogeochemical cycling of nutrient elements mediated by microorganisms in sediment and seawater. The microorganisms inhabiting seagrass meadows have essential roles in promoting plant growth by producing auxin, liberating nutrients from OM [9], suppressing pathogens [10,11], and facilitating sulfide detoxification [12]. In such an ecologically important ecosystem, however, information on less abundant yet equally crucial archaeal communities remain scarce.

Archaea, one of the three domains of life, are an important contributor to ammonia oxidation, methane metabolism, and OM degradation [13-15]. Much effort has been made to understand the genetic diversity and community composition of archaea in coastal 
marine ecosystems using the $16 \mathrm{~S}$ rRNA gene as a molecular marker [16]. Recently, a spatial comparison of the archaeal community among seagrass meadows was reported $[17,18]$. Seagrass vegetation selectively enriched Woesearchaeota (Woese-3 and Woese-21), Bathyarchaeota (Bathy-6 and Bathy-18), as well as methanogenic archaea [18,19], revealing that there is ecological niche separation of archaeal taxa between seagrass-vegetated and adjacent unvegetated sediments [18]. Beyond seagrass ecosystems, the spatial patterns in archaeal distribution have been described for several coastal marine environments, including the Antarctic coastal waters [20], mangrove and intertidal wetland mudflats [21,22], the coast of the North Sea [23], and Shark Bay mats [24]. In contrast to the increasing knowledge gleaned from spatial variations in archaeal communities and their niche preferences, much less is known about archaeal seasonal dynamics and their ecological potentials in seagrass sediments, even though seagrass-associated bacterial and microeukaryotic communities do exhibit distinct seasonal or annual variations $[25,26]$.

Different archaeal taxa play different ecological roles in coastal marine ecosystems. For example, several clades of the Thaumarchaeota are capable of acetate assimilation [27]. Members of Euryarchaeota are functionally diverse (autotrophs, heterotrophs, chemolithotrophs), being abundant in marine waters [28]. Several Bathyarchaeota lineages have been suggested for their capacity for methane production [29], $\mathrm{CO}_{2}$ fixation via acetogenesis [30], and dissimilatory nitrite reduction to ammonium [31]. The efficiency with which archaea fulfill these functions is undoubtedly affected by their physical and chemical environments, which vary enormously with seasonal changes in temperate seagrass ecosystems. Therefore, this raises the question of whether composition and functions of archaeal assemblages exhibit different seasonal patterns in coastal seagrass sediments.

In this study, we sampled Z. japonica-colonized surface sediments spanning four seasons from two seagrass habitats around the peninsula of Shandong province on the northern Chinese Bohai Sea coast, where seasons are climatically highly variable. Seasonal changes in physicochemical properties were also investigated to identify key environmental factors that regulate the archaeal community structure (ACS). Based on 16S rRNA gene information, the differentiation of functional potentials (e.g., carbon fixation and degradation, and nitrogen, sulfur, and phosphorous metabolisms) among four seasons was predicted. Here, we addressed the following questions: (i) What is the seasonal distribution pattern of the archaeal community in Z. japonica meadows? (ii) What are the major environmental drivers attributed to the seasonal pattern? (iii) Do seasonal changes affect the stability of archaeal ecological functions? By answering the above questions, we aim to reveal the seasonal dynamic and ecological functions of benthic archaeal communities in seagrass Z. japonica ecosystems.

\section{Materials and Methods}

\subsection{Study Site and Sampling}

Two seagrass beds of Z. japonica in Weihai City (abbreviation for WH) and Dongying City (DY) were selected for sampling in temperate coastal areas of northern China (Figure S1). WH $\left(37^{\circ} 20^{\prime} 56.52^{\prime \prime} \mathrm{N}, 122^{\circ} 36^{\prime} 14.29^{\prime \prime} \mathrm{E}\right)$ is a shallow lagoon ecosystem with an area of $4.8 \mathrm{~km}^{2}$, situated in the southeast of Chengshan Town, Weihai City, Shandong Peninsula. The sediments are mainly sandy with a mean grain size (GS) of $218.1 \mu \mathrm{m}$, rich in OM (Table S1). The annual mean water temperatures are between 1.2 and $29.1^{\circ} \mathrm{C}$, and salinity is approximately $32.6 \%$ (Table S1). DY $\left(37^{\circ} 51^{\prime} 4.21^{\prime \prime} \mathrm{N}, 119^{\circ} 6^{\prime} 11.05^{\prime \prime} \mathrm{E}\right)$ is an open coast adjacent to the Yellow River Delta, located in Kenli County, Dongying City, Shandong Province. The seagrass Z. japonica in DY grows on the muddy seafloor with a mean GS of $95.1 \mu \mathrm{m}$, together with a high nitrate concentration (Table S1). The annual water temperatures are between -2 and $29.6{ }^{\circ} \mathrm{C}$, and salinity is approximately $20.3 \%$ (Table S1).

A total of 24 (3 samples $\times 2$ sites $\times 4$ seasons) Z. japonica sediment samples from 2 sampling areas across 4 seasons were collected during 2018. At each location, 3 surface sediments (top $5 \mathrm{~cm}$ layer) in Z. japonica-vegetated regions were sampled randomly using 
a custom-made corer $(1 \mathrm{~cm}$ in diameter) during the low tide period. The homogenized surface sediments were immediately transported to the laboratory and stored at $-80^{\circ} \mathrm{C}$ until DNA extraction.

The measurement methods of physicochemical parameters in overlying water and sediments were as previously described [32]. Physicochemical parameters of overlying water include dissolved oxygen (DO), temperature, $\mathrm{pH}$, and salinity; and sedimentary parameters include GS, total organic carbon (TOC), total organic nitrogen (TON), nitrite, and nutrients (nitrate, ammonium; Table S1).

\subsection{DNA Extraction and ILLUMINA Sequencing}

Genomic DNA extraction from the sediment samples was undertaken using the FastDNA Spin Kit for Soil (MP Biomedical, Santa. Ana, CA, USA) according to the manufacturer's recommendations. The V4-V5 hypervariable region of $16 \mathrm{~S}$ rDNA was amplified using archaeal universal primers 524F10extF (5'-TGYCAGCCGCCGCGGTAA-3') and Arch958RmodR (5'-YCCGGCGTTGAVTCCAATT-3') [33]. Each sample was distinguished by a paired specific 6-bp barcode. PCR reaction mixture $(20 \mu \mathrm{L})$ contained $4 \mu \mathrm{L}$ of $5 \times$ FastPfu Buffer (Transgen, Beijing, China), $0.8 \mu \mathrm{L}$ of each primer $(5 \mu \mathrm{M}), 2 \mu \mathrm{L} 2.5 \mathrm{mM}$ of dNTPs, $0.4 \mu \mathrm{L}$ of FastPfu polymerase (Transgen), and $10 \mathrm{ng}$ of template DNA. The PCR was performed with a T100 Thermal Cycler (Bio-Rad, Hercules, CA, USA) with an initial denaturation at $95{ }^{\circ} \mathrm{C}$ for $3 \mathrm{~min}$, followed by 27 cycles of denaturation at $95^{\circ} \mathrm{C}$ for $30 \mathrm{~s}$, annealing at $55^{\circ} \mathrm{C}$ for $30 \mathrm{~s}$, and elongation at $72{ }^{\circ} \mathrm{C}$ for $45 \mathrm{~s}$, with the final extension at $72{ }^{\circ} \mathrm{C}$ for $10 \mathrm{~min}$. The PCR products were extracted from $2 \%$ agarose gels and purified using an AxyPrep DNA Gel Extraction Kit (Axygen Biosciences, Union City, CA, USA). Paired-end libraries were generated using an NEB Next Ultra DNA Library Prep Kit for the Illumina MiSeq platform (Illumina, San Diego, CA, USA) by Majorbio Bio-Pharm Technology Company (Shanghai, China).

\subsection{Sequence Processing, Diversity Analysis, and Predicted Functional Profiles}

To infer amplicon sequence variants (ASVs), demultiplexed and quality-filtered reads were processed through the DADA2 pipeline (DADA2 package v1.14.1) [34] in $\mathrm{R}$ (v3.6.3) [35]. We firstly used Cutadapt (v1.18) [36] to trim primer parts of the 16S rRNA gene sequences. Then, sequence lengths shorter than $180 \mathrm{bp}$ were excluded using the command filterAndTrim in DADA2 (with other parameter arguments: $\operatorname{maxEE}=\mathrm{c}(3,5)$, $\max N=0$, truncQ $=2$, rm.phix $=$ TRUE). Error models were generated for filtering forward and reverse reads by using the command learnErrors, which were then used to infer true sequence variants using the core DADA2 algorithm with pool argument set to pseudo. Forward and reverse reads were merged using the command mergePairs, and chimeras were eliminated using the removeBimeraDenovo command. The IdTaxa command of package DECIPHER (v2.14.0) [37] was used for taxonomic assignments against the SILVA_SSU_v138 database.

Sequences assigned into non-archaea and unclassified taxa were removed manually. Alpha diversity estimators of archaea were measured based on rarefied data using the phyloseq v1.22.3 package [38]. Rarefaction curves were depicted to assess the effects of sequencing depth on the obtained species richness. Beta diversity was calculated with the weighted UniFrac distance and was visualized using principal coordinate analysis $(\mathrm{PCoA})$ in $\mathrm{R}$ with Vegan and ggplot2 packages $[39,40]$. LEfSe (linear discriminant analysis effect size) [41] with $p$-value cutoff 0.05 and LDA size effect value of 3.5 was applied to discover statistically different biomarkers among four seasons. In order to investigate seasonal variations of functional potentials of archaeal community, functional profiles were predicted using the Tax4Fun2 package in R [42]. Tax4Fun2 predicted the functional profiles by aligning the $16 \mathrm{~S}$ sequence against the in-built reference dataset to identify the nearest neighbor. Subsequently, it calculated the metabolic potential by linking the abundance profile to the Kyoto Encyclopedia of Genes and Genomes (KEGG) Orthology (KO) database. Metabolic pathway abundance was normalized by $16 \mathrm{~S}$ rRNA gene copy number. 


\subsection{Phylogenetic Analysis of Bathyarchaeota Sequences}

Since the majority of the sequences were assigned into phylum Bathyarchaeota, phylogenetic analyses were performed to further resolve their taxonomic ranks using maximum likelihood (ML) algorithm. Reference sequences for typical Bathyarchaeota subclades proposed by Zhou et al. [43] were downloaded and aligned with MAFFT v7.4 [44]. The ML analysis was constructed using the RAxML v8.0 software [45] with 1000 bootstrap replicates and the GTRGAMMAI model, the best suggested by the jModeltest2 program [46].

\subsection{Statistical Analysis}

One-way ANOVA with LSD post hoc test was performed to examine the differences in environment factors, alpha diversity estimators, and functional category of benthic archaea among four seasons. Spearman's rank correlation analysis was conducted to test the associations between the relative abundance of a specific taxon and environmental variables. All these analyses above were executed using SPSS v.20 software (SPSS, Chicago, IL, USA).

To test the dissimilarity in ACS among sample groupings, ANOSIM (analysis of similarity) was performed based on weighted UniFrac metrics, using $\mathrm{R}$ with package Vegan [47]. The relationships between environmental variables and ACS were determined by conducting redundancy analysis (RDA) and simple Mantel test, using vif.cca and mental functions of the Vegan package in $R$, respectively.

\section{Results}

\subsection{Seasonal Variations in Physicochemical Parameters}

The average seawater temperature increased up to $29^{\circ} \mathrm{C}$ in summer and dropped to $-0.3{ }^{\circ} \mathrm{C}$ in winter (ANOVA, $p<0.001$ ). The highest values of $\mathrm{pH}(8.3)$ and nitrite $\left(29.3 \mu \mathrm{mol} \mathrm{kg}^{-1}\right)$ were both observed in spring. The ammonium concentrations exhibited a contrasting trend to temperature, with the highest content in winter $\left(932.6 \mu \mathrm{mol} \mathrm{kg}{ }^{-1}\right)$ and lowest content in summer $\left(382.6 \mu \mathrm{mol} \mathrm{kg}{ }^{-1}\right)$. However, other environmental factors (e.g., $\mathrm{pH}, \mathrm{GS}$, salinity, TOC, TON, nitrate) showed no significant difference with seasonal variations $(p>0.05$; Table S1).

\subsection{Variations in Alpha Diversity of Benthic Archaea Community}

After quality filtering, a total of 1,668 ASVs were generated from 453,806 raw sequences derived from 24 samples (Table S2). Based on Good's coverage, the mean of sampling completeness was $99.96 \%$ (ranging from 99.89 to $99.99 \%$; Table S2), in line with the species rarefaction curves with clear asymptotes (Figure $\mathrm{S} 2$ ). This suggests that the majority of the archaeal phylotypes in seagrass sediments were identified.

Alpha diversity estimators of archaea varied greatly among four seasons, with ASV richness ranging from 126 264, Chao1 indices from 126 267, Shannon indices from 5.1 7.1, and Simpson from 0.92 0.99 (Figure 1). The highest means of Shannon and Simpson indices were observed in summer, significantly different from those in autumn and winter $(p<0.049$ for Simpson). Nevertheless, there were no considerable differences in ASV richness and Chao 1 indices between seasons $(p>0.05$, Figure 1).

At a $100 \%$ similarity threshold, the ASV numbers were mainly assigned to phylum Crenarchaeota (68.5\% of sequence number), followed by Thermoplasmatota (18\%), Asgardarchaeota $(5.3 \%)$, and Halobacterota $(1.9 \%$; Figure 2A). The average ASV richness of the major phyla was calculated individually to examine their seasonal variations (Figure 3), from which most season-wise differences were statistically significant $(p<0.05)$, except for Asgardarchaeota (Figure 3C). Specifically, Halobacterota, Asgardarchaeota, Aenigmarchaeota, and Euryarchaeota generally had a higher richness in spring than those in other seasons (Figure 3C-F). Meanwhile, the lowest richness of Crenarchaeota and the highest richness of Thermoplasmatota were both detected in summer (Figure 3A,B). 

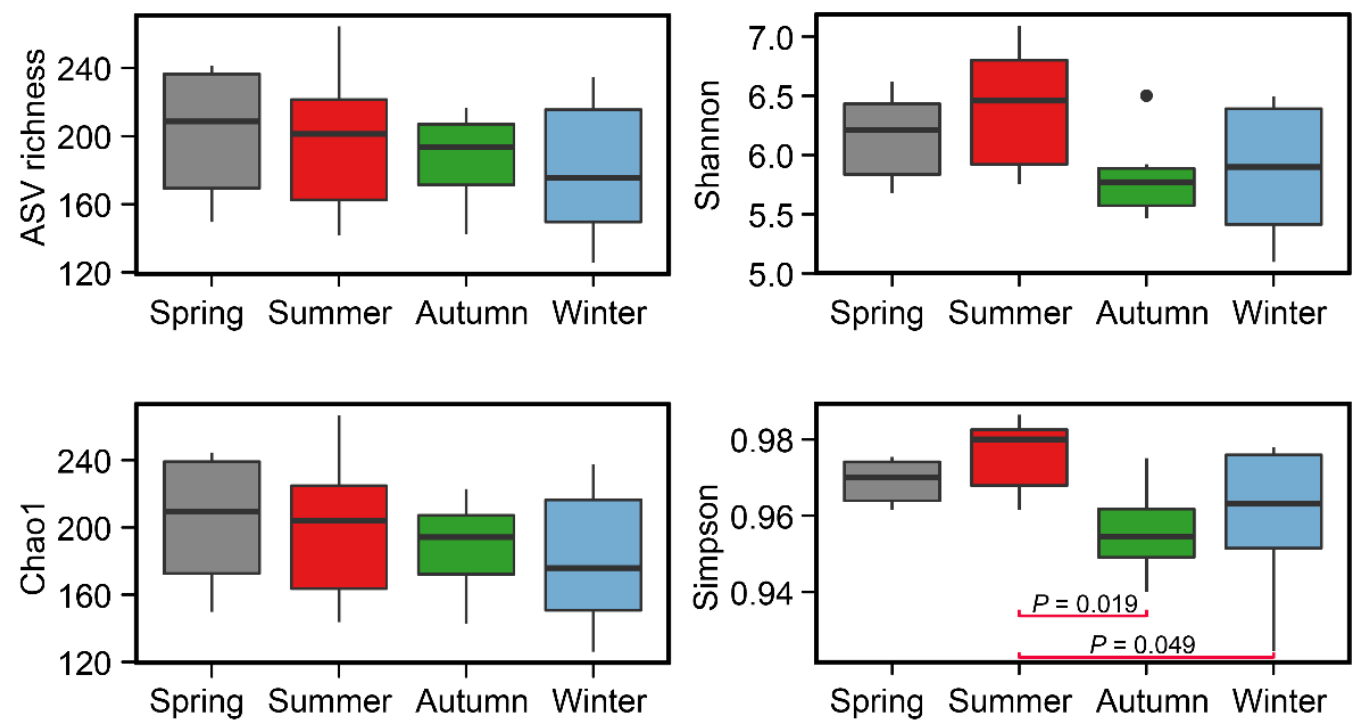

Figure 1. Comparisons of alpha diversity estimators of benthic archaea community. $p$ values are given for the comparisons among seasons (spring, summer, autumn, and winter) using one-way ANOVA $(n=6)$.

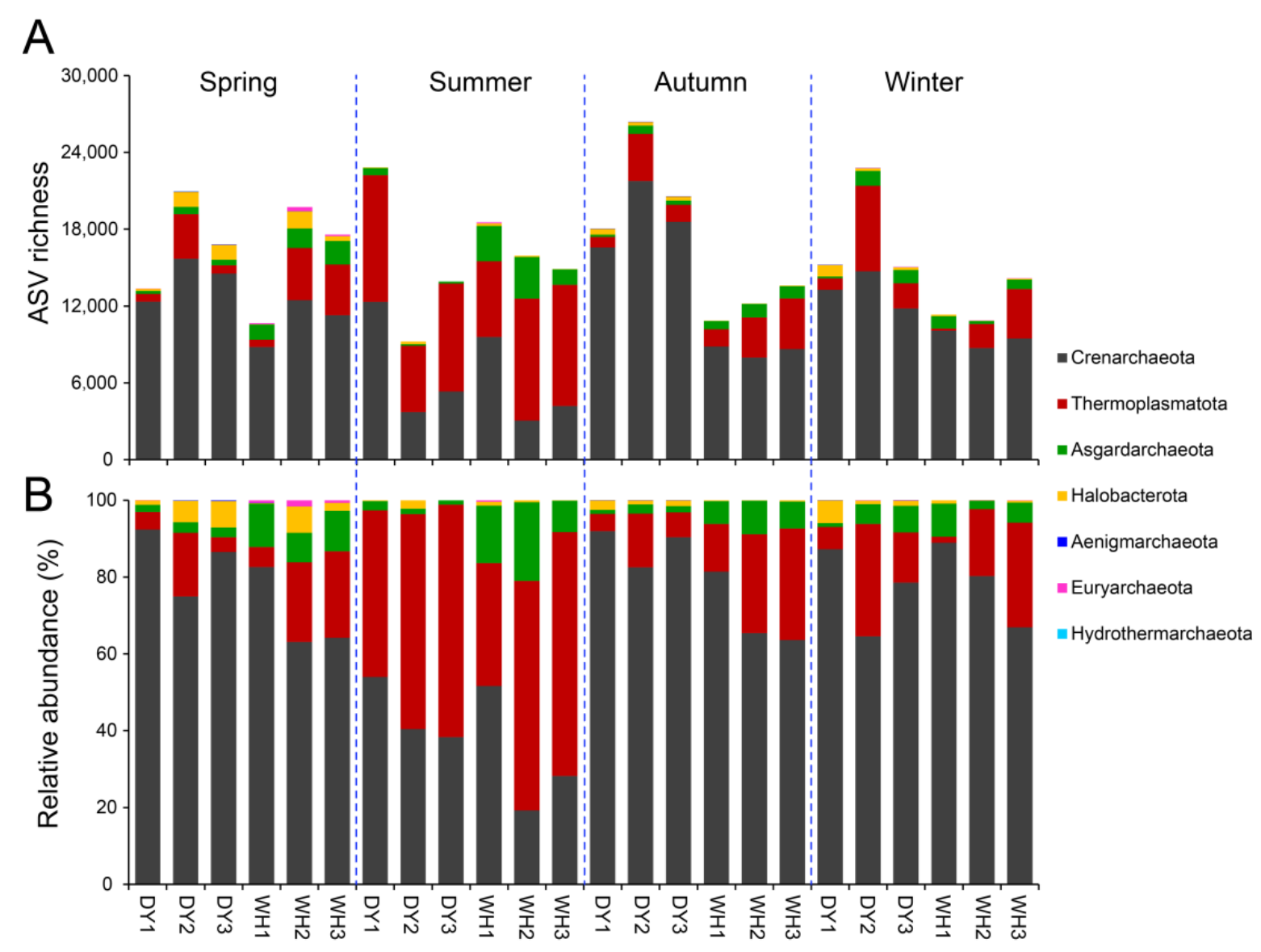

Figure 2. Variations in amplicon sequence variant (ASV) richness and composition of benthic archaeal community in temperate seagrass meadows. Overall ASV number of different phyla in different seasons (A). Relative proportions of reads classified at the phylum level across samples collected in four seasons (B). 
(A) Crenarchaeota

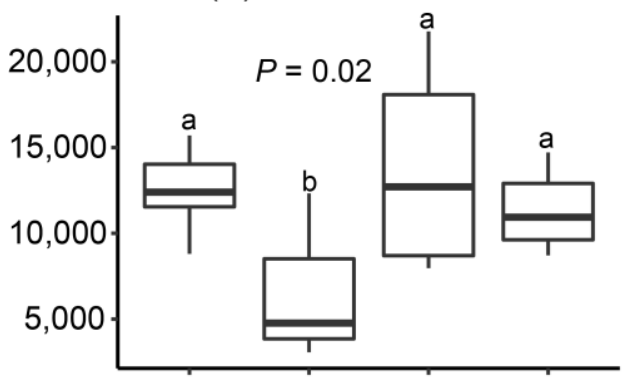

(C) Asgardarchaeota

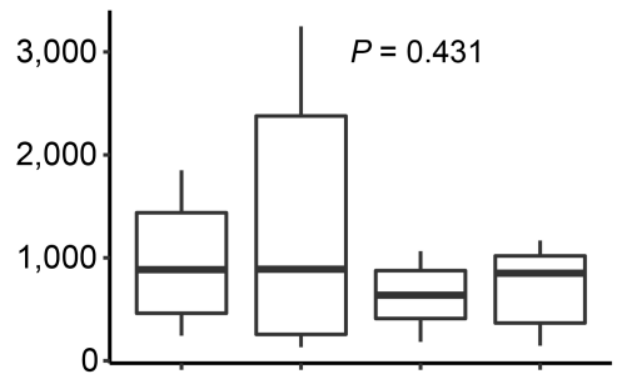

(E) Aenigmarchaeota

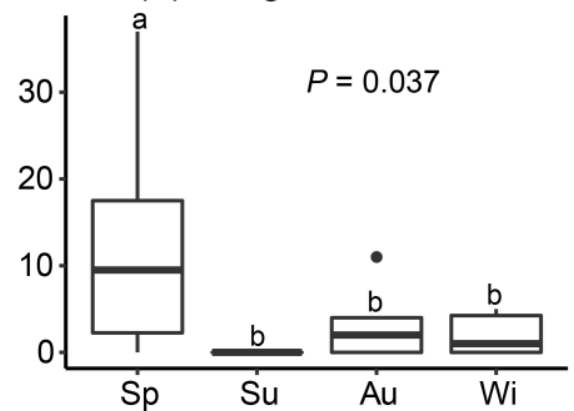

(B) Thermoplasmatota

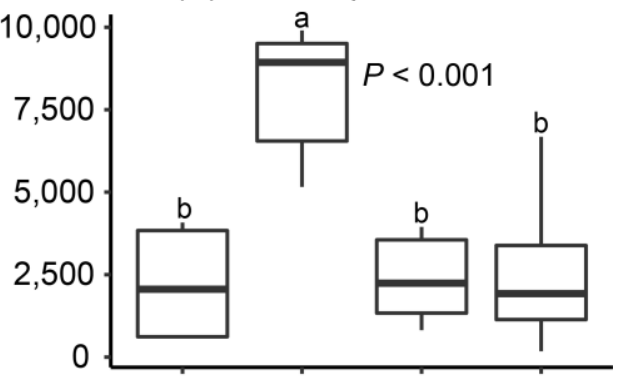

(D) Halobacterota

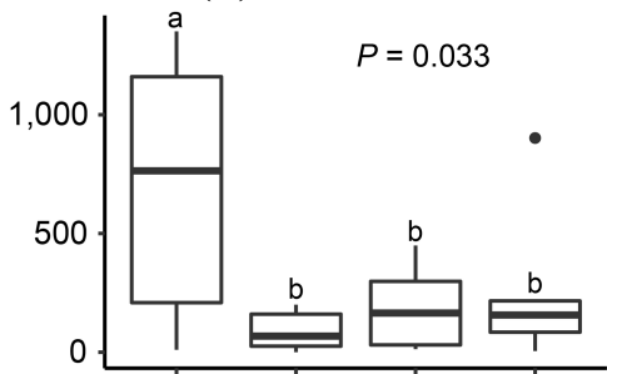

(F) Euryarchaeota

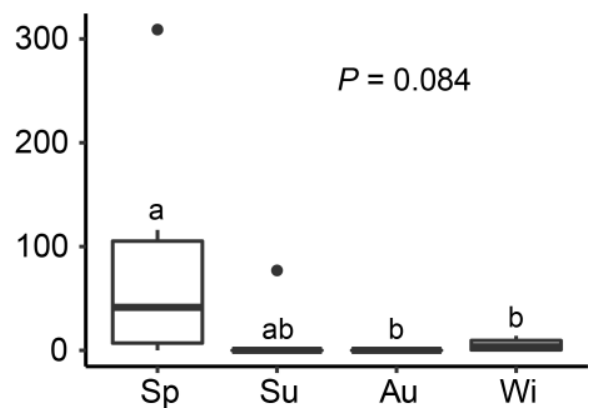

Figure 3. Comparisons of amplicon sequence variant (ASV) richness of the archaeal major phyla (A, Crenarchaeota; B, Thermoplasmatota; C, Asgardarchaeota; D, Halobacterota; E, Aenigmarchaeota; and F, Euryarchaeota) among four seasons. Mean values with different letters, determined by ANOVA with LSD post hoc test $(n=6)$, indicate significant differences $(p \leq 0.05)$. Abbreviations: Sp, spring; Su, summer; Au, autumn; Wi, winter.

\subsection{Archaeal Community Composition and Bathyarchaeota Populations}

Overall, the sequences of benthic archaeal communities were dominated by Crenarchaeota ( $68.2 \%$ of relative abundance), followed by Thermoplasmatota (24\%), Asgardarchaeota (5.9\%), and Halobacterota (1.8\%; Figure 2B). The other three taxa (Aenigmarchaeota, Euryarchaeota, and Hydrothermarchaeota) were much rarer, with total proportions less than $1 \%$ (Figure 2B). Within Crenarchaeota, the sequences were primarily assigned to Bathyarchaeota (60.3\% of all archaeal sequences) and class Nitrososphaeria (6.6\%). Class Thermoplasmata was mainly represented by Marine Benthic Group D (MBG-D, 22.5\%).

Within Bathyarchaeota, the sequences were classified into six subclades according to the classification proposed by Zhou et al. [43] (Figure 4). Bathy-15 (36.4\% of all archaea), Bathy-8 (14.7\%), and Bathy-6 (7.1\%) were the major subclades among all samples (Figure 4A). In seasonal comparisons, these subclades exhibited a similar pattern in that they generally had lower relative abundance in summer. In particular, the relative abundance of Bathy-15 was significantly different among seasons ( $p=0.002$, Figure 4 B). 

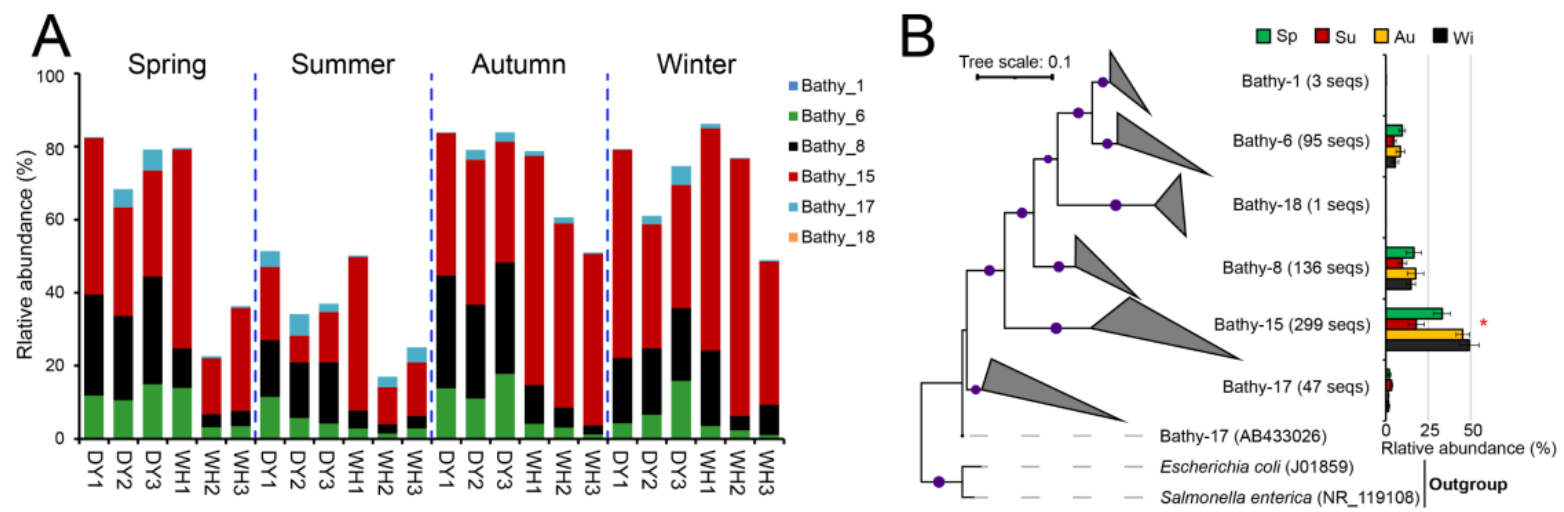

Figure 4. The proportions of Bathyarchaeota subclades (A). The maximum likelihood (ML) tree based on 16S rRNA genes shows the phylogeny of Bathyarchaeota subclades, and the bar plots show the specific-taxa relative abundances among four seasons $(n=6)(B)$. Abbreviations: Sp, spring; Su, summer; Au, autumn; Wi, winter.

\subsection{Seasonal Variability of Benthic Archaeal Communities in Z. japonica Meadows}

The difference in ACS was statistically significant among four seasons (ANOSIM, $p<0.013$; Table 1), regardless of the samples from two habitat types being considered collectively or separately. In particular, the ACS in summer samples was more divergent and well separated from other seasons in both habitats (Figure 5). Furthermore, differentiated seasonal distributions of several archaeal taxa were analyzed using LEfSe (Figure 6). Methanobacteria (within Euryarchaeota), Nitrosopumilales, and their subcategories shown in the diagram (Figure 6), together with genus Methanolobus, were enriched in the spring. The phylum Thermoplasmatota, class Thermoplasmata, MBG-D, and uncultured archaeon affiliated to MBG-D were more abundant in the summer. Besides, Bathyarchaeota (within Crenarchaeota) and their subordinate order to genus were enriched in relative abundance in the autumn. However, no clades were consistently presented in the winter (Figure 6).

Table 1. ANOSIM testing the seasonal differences in benthic archaeal community structure based on weighted UniFrac metrics.

\begin{tabular}{|c|c|c|c|c|c|c|}
\hline \multirow{2}{*}{ Grouping } & \multicolumn{2}{|c|}{ All Samples $(n=6)$} & \multicolumn{2}{|c|}{ Within WH $(n=3)$} & \multicolumn{2}{|c|}{ Within DY $(n=3)$} \\
\hline & $R$ & $p$ & $R$ & $p$ & $R$ & $p$ \\
\hline Season (global test) & 0.337 & 0.001 & 0.869 & 0.001 & 0.426 & 0.013 \\
\hline Spring vs. Summer & 0.761 & 0.002 & 0.761 & 0.002 & 0.593 & 0.100 \\
\hline Spring vs. Autumn & -0.02 & 0.452 & -0.020 & 0.452 & 0.111 & 0.500 \\
\hline Spring vs. Winter & -0.013 & 0.432 & -0.013 & 0.432 & 0.037 & 0.300 \\
\hline Summer vs. Autumn & 0.787 & 0.002 & 0.815 & 0.002 & 0.630 & 0.100 \\
\hline Summer vs. Winter & 0.759 & 0.002 & 0.833 & 0.002 & 0.667 & 0.100 \\
\hline Autumn vs. Winter & -0.169 & 0.959 & 0.792 & 0.100 & 0.111 & 0.500 \\
\hline
\end{tabular}

Notes: significant $p$-values $(\leq 0.05)$ are highlighted in bold.

\subsection{Environmental Drivers of Variation in Archaeal Community Structure}

The effects of environmental variables on benthic ACS were examined using RDA (Figure 7A) and the simple Mantel test (based on Bray-Curtis and Jaccard distances; Table S3). When all seasonal data were taken into consideration, the community dissimilarity was significantly correlated with overall environmental factors measured in this study $(R=0.378, p=0.001$; Table S3), among which salinity, TOC, and TON were the most important driving factors both in RDA $(p<0.001$, Figure 7A) and the Mantel test $(p<0.006$, Table S3). 


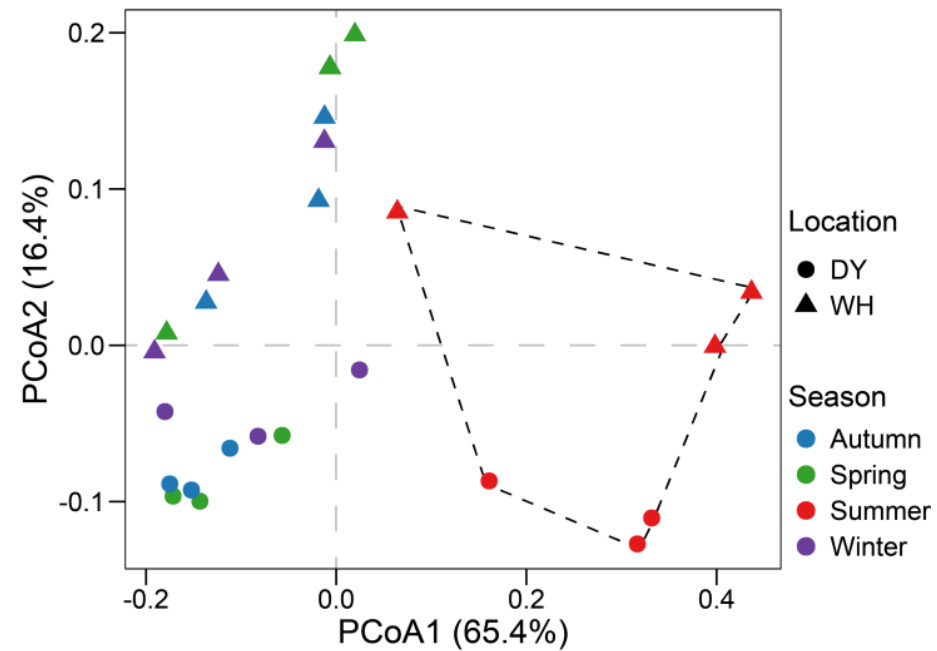

Figure 5. Principal Coordinate Analysis (PCoA) based on the weighted UniFrac distance showing the differences in community structure of archaea collected from different seasons.
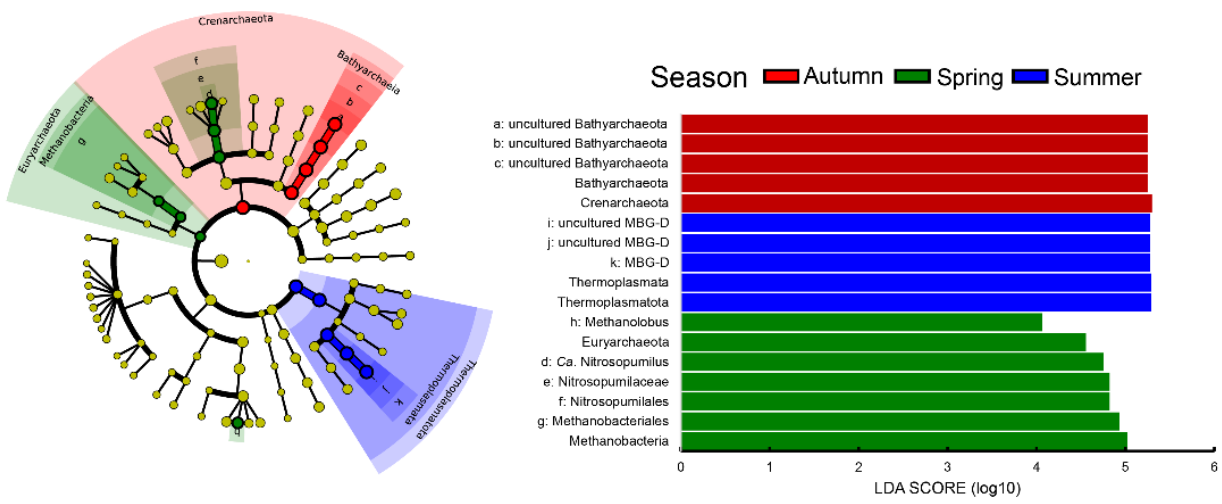

Figure 6. Taxonomic cladogram indicating the phylogenetic distribution of the archaeal lineages in terms of season categories; only lineages with linear discriminate analysis (LDA) values $>3.5$ (as determined by LEfSe) are displayed $(n=6)$. Circles of radiation from inside to outside indicate phylogenetic levels from phyla to genus. Phyla and classes are labeled. The diameter of each small colored circle is proportional to the relative abundance of the given taxon. Pre-sample normalization is used to standardize the relative abundance, and all-against-all strategy is used in the step of multi-class analysis.

Furthermore, the associations between environmental factors and the relative proportion of major archaeal groups were also explored using Spearman's correlation analyses (Figure 7B). Among Bathyarchaeota, the relative abundances of Bathy- 6 and Bathy- 8 were positively correlated with $\mathrm{pH}(\rho>0.51, p<0.041)$, but negatively correlated with TOC, TON, and salinity concentrations $(\rho<-0.62, p<0.007)$. The proportions of Bathy- 8 and Bathy-17 were significantly and negatively correlated with sedimentary GS $(\rho<-0.50, p<0.041)$. DSEG, Halobacteria, and Methanosarcinia were more abundant in the sediments with lower TON and TOC concentrations $(\rho<-0.44, p<0.033)$. In contrast, Odinarchaeia and Bathy-1 were richer in the sediments with higher TOC $(\rho>0.43, p=0.004)$, TON $(\rho=0.43, p=0.02)$, and salinity $(\rho=0.47, p=0.03)$. Additionally, the relative abundance of Lokiarchaeota was positively related to TOC and salinity $(\rho>0.49, p=0.03)$. 


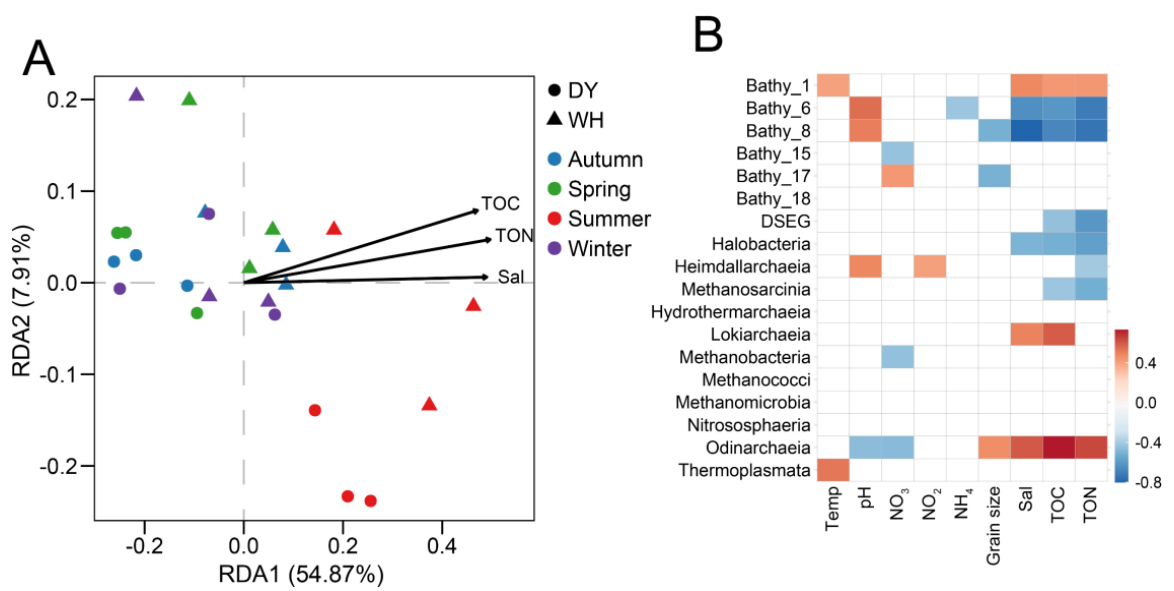

Figure 7. The redundancy analysis (RDA) plot showing relationships between archaeal community and environmental variables (A). A heatmap showing correlation coefficients $(\rho)$ between relative abundance of major taxa of archaea at class level and environment factors (B). Only significant correlations $(p<0.05)$ are shown in both analyses. The values of correlation coefficients are indicated according to the scale bar. Abbreviations: TOC, total organic carbon; TON, total organic nitrogen; Sal, salinity; Temp, temperature.

\subsection{Seasonal Variation in the Functional Profiles}

The seasonality of archaeal potential functions was illustrated using principal component analysis (PCA; Figure S3). Genes associated with carbon (including methane) and sulfur metabolisms in summer were distinct from those in winter (Figure S3). Although nitrogen metabolism genes were seemingly separated between seasons, spring and winter samples were grouped more closely (Figure S3). Additionally, genes related to carbon degradation (cellulases and hemicellulases) showed significantly higher abundance in summer than those in spring $(p<0.05$; Figure 8$)$. The highest proportion of methane metabolism genes occurred in winter $(p<0.05$; Figure 8$)$. Yet, the relative abundances of genes involved in the Calvin cycle and nitrogen, sulfur, and phosphorous metabolisms did not exhibit significant differences across seasons (Figure 8).
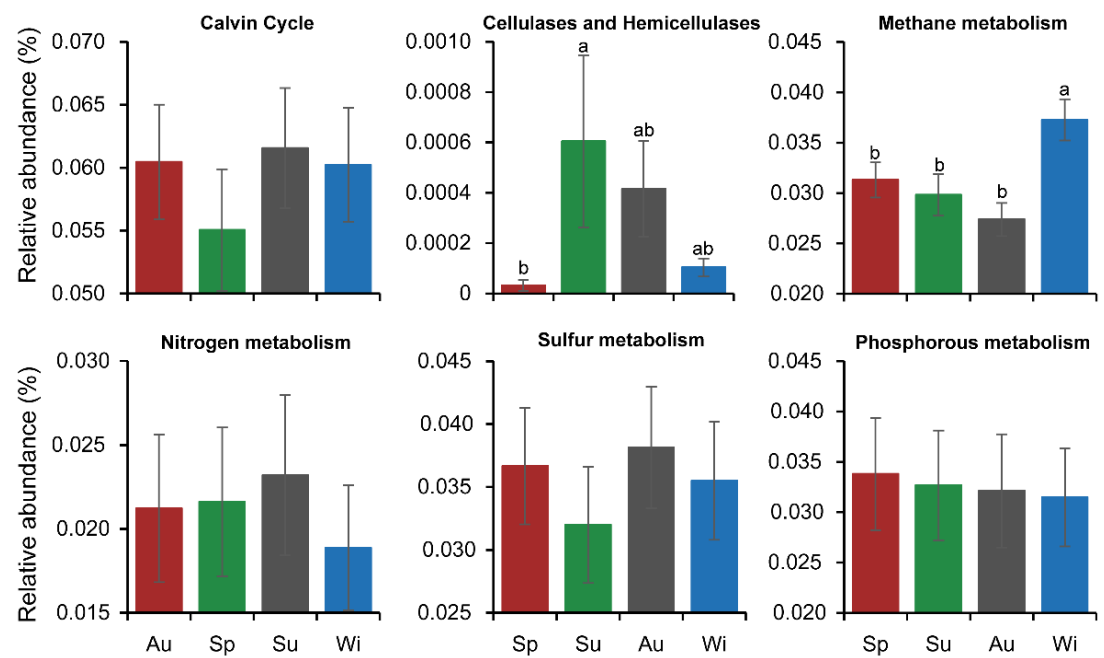

Figure 8. Comparisons of the relative proportions of genes involved in key energy pathways across four seasons using one-way ANOVA with LSD test $(n=6)$. Functional profiles were predicted from the KEGG hierarchy with Tax4Fun2 [42]. Genes involved in different metabolic modules are listed in Supplementary Table S4. The error bars indicate standard errors, and different letters above the bars indicate significant differences $(p<0.05)$. Abbreviations: Sp, spring; Su, summer; Au, autumn; Wi, winter. 


\section{Discussion}

Archaea are an indispensable component of sedimentary ecosystems, playing a critical role in benthic biogeochemical cycles in seagrass ecosystems [18,48,49]. Exploring the seasonal dynamic of archaeal communities associated with seagrass meadows could contribute to a better understanding of ecology features and adaptive mechanisms for marine archaea. To the best of our knowledge, this study provides the first investigation of the seasonal distribution patterns of archaeal community assembly, along with their metabolic functions, in seagrass meadow systems.

In the present study, the relative abundance of Bathyarchaeota was up to $60.3 \%$ of the total archaeal community in Z. japonica meadows (Figure 2). Bathyarchaeota (formerly called Miscellaneous Crenarchaeota Group, MCG) is widely distributed and highly abundant in anoxic and organic-rich sediments, including seafloors and estuaries [50,51]. Previous work reported that the addition of biopolymer lignin could significantly stimulate the growth of Bathyarchaeota [52]. Lignin is an important component of seagrass cell walls, and it can be accumulated to a high concentration in seagrass sediments [53-55]. Therefore, the enrichment of Bathyarchaeota in Z. japonica meadows was probably attributed to the presence of biopolymer lignin. In return, Bathyarchaeota contributes importantly towards the degradation of seagrass biomass due to their versatility in metabolic capabilities, which are capable of using a wide range of substrates, such as plant-derived mono- and polysaccharides, detrital proteins, methane and methylated compounds, and other recalcitrant OM $[14,31,56]$.

Although members of Bathyarchaeota were prevalent in the sedimentary environments of Z. noltii [48] and Z. marina meadows [18,49] as well, Woesearchaeota $(42 \%)$ dominated the benthic archaeal community in Z. marina sediments [18]. Within clade Bathyarchaeota, Bathy17 dominated in Z. marina sediments, while Bathy- 15 dominated in Z. japonica meadows. These disparities indicated that the distribution patterns of these Bathyarchaeota groups seemed to be selected by the environmental heterogeneity of different seagrass species. Z. japonica meadows are often found in intertidal zones with a large GS $(156.6 \mu \mathrm{m})$ and a relatively low nitrate concentration $(24.8 \mu \mathrm{M})$, while Z. marina meadows are usually distributed in subtidal zones that possess a small GS $(55.3 \mu \mathrm{m})$ and high nitrate concentration $(35.9 \mu \mathrm{M})$ [32]. According to the results of Spearman's correlation, the proportion of Bathy17 was positively correlated with nitrate and negatively correlated with GS (Figure 7B), but Bathy-15 was correlated negatively with nitrate concentrations, consistent with the niche preference of the two Bathy subclades between seagrass Z. marina [18] and Z. japonica meadows. Moreover, it has been reported that the growth of Bathy- 15 and Bathy- 17 was strongly stimulated by coastal vegetation (seagrass or mangrove) colonization $[18,57]$. Therefore, we speculated that abiotic factors and biotic factors (species-specific effect of seagrass) jointly promoted the enrichment of Bathyarchaeota subgroups in different seagrass systems, but more investigations in situ and physiological studies are necessary to verify this hypothesis.

The seasonal differences in microbial communities are often characterized by taxonomic community composition variations, which are caused by temporary species acquisition during favorable growing seasons and temporary species loss during unfavorable conditions [58]. The seasonal difference of physicochemical parameters is a crucial factor driving the microbial shifts, which may further affect the stability of microbial ecological function.

In the present study, both alpha (Shannon and Simpson) and beta diversities of the archaeal community exhibited significant seasonal fluctuations in Z. japonica systems (Figures 1 and 5; Table 1). The highest archaeal diversity was detected in summer (Figure 1), corresponding with the peak in OM (TOC and TON) contents (Table S1). Abundant OM from the decomposition of seagrass litters generally converts into more bioavailable nutrients [59,60], which support the proliferation of heterotrophic archaea species. Then, the cohabitation of various metabolic microflora is fueled, developing thriving archaeal communities in the summertime. Thermoplasmatota is an important contributor to the 
high species richness in summer (Figure 3), which was significantly positive with water temperature, indicating that some members of Thermoplasmatota have advantages under high-temperature conditions [61]. Besides, the lowest diversity occurred in the autumn (Figure 3). With the decrease in nutrients in the autumn, rare taxa are no longer selected because fast-growing dominant taxa can effectively compete for the available nutrients. Thus, the low diversity is due to the dominance of a few species, resulting in a low evenness of the archaeal communities [58].

For the beta diversity, seasonality also separated archaeal communities into corresponding assemblages by PCoA based on the UniFrac matrix method (Figure 5), suggesting that the sequence abundance of ASVs from each archaeal phylogenetic lineage influenced the distribution pattern of overall ACS. RDA and the Mantel test (Figure 7A; Table S3) were applied to delineate any significant correlation between the archaeal community dissimilar distance matrix and the environment factor distance matrix, and results revealed that TOC, TON, and salinity were the most important driving factors, significantly correlated with the archaeal community distribution pattern among all the samples. Based on the Spearman correlation analysis, TOC, TON, and salinity were also the most prevalent influential parameters, significantly correlated with the relative abundance of major archaeal taxa, either positively or negatively. In addition to OM contents, salinity is often the most vital driver of benthic microbial communities [62]. Archaea in seagrass sediments may be sensitive to salinity change between seasons for an extensive salinity range from summer $(31.1 \pm 3.2 \%$ o $)$ to autumn $(20.9 \pm 4.7 \%$ o $)$. Most of the archaea taxa in Z. japonica-colonized sediments were negatively correlated with salinity, whereas Bathy-1 and Odinarchaeia were positively correlated with salinity, leading to a potential succession of archaeal community composition along with salinity change.

The temporal fluctuation of each archaeal phylogenetic lineage plays a role in driving the seasonal variation of the whole ACS, resulting in corresponding shifts in the community's functions. In this study, several archaeal taxa showed apparent seasonal preference (Figures 3 and 4), which may be related to the shifts of environmental parameters and seagrass biomass at different growth stages. Methanogenic archaeal taxa (order Methanobacteriales and genus Methanolobus) were more abundant in spring than in other seasons. However, based on the predictive profiles by Tax4Fun2, archaeal functional potential related to methane metabolism was much higher in winter (Figure 8), which is likely induced by the abundant decaying OM (e.g., humic substances) and anaerobic conditions in winter sediments [63]. On the other hand, low temperatures may inhibit the growth of methanogens to a certain extent during winter, because the genus Methanolobus have the most efficient methanogenesis at $15{ }^{\circ} \mathrm{C}$ [64], approaching the spring seawater temperature $\left(12.6^{\circ} \mathrm{C}\right)$ within $\mathrm{Z}$. japonica meadows. Therefore, the elevated temperature and inputs of various nutrients during spring effectively facilitated methanogenic activities.

Moreover, we observed that MBG-D predominated in archaea groups in the summer sediments (Figure 6). Lloyd et al. [14] reported that MBG-D single-cell genomes contain a high content of predicted extracellular peptidases, indicating that they may contribute significantly to the degradation of detrital peptides in sediments during the vigorous growth period of seagrass. The Tax4Fun2 predictive profiles showed a marked peak of relative abundance related to cellulose and hemicellulose degradation genes in the summer, and subsequently decreased gradually (Figure 8). A similar increase in the gene abundance of $\mathrm{C}$ degradation in summer was also observed in temperate deciduous forest ecosystems [65]. These results correspond to the increased plant litter in summer and the decomposition in the following seasons. Curiously, in the eutrophic summer, the proportions of Bathy-15 significantly descended (Figure 4). The Spearman's correlation showed that Bathy-15 was significantly negatively correlated with nitrate, which exhibited a pronounced peak in the summer. In addition, it has been demonstrated that $\mathrm{OM}$ is an important limiting factor for the growth of Bathy-15 in oligotrophic environments [66]. However, seagrass meadows could provide a high quantity of OM for the growth of microorganisms. Therefore, the weak correlation between OM (TOC and TON) contents 
and Bathy-15 relative abundance (Figure 7) therein suggested that members of Bathy-15 may selectively assimilate OM in eutrophic environments, such as root exudates [18]. Alternatively, the promoting effect of high OM on other archaeal groups was greater than that on Bathy-15 [57], like MBG-D mentioned above. Thus, the proportion of Bathy-15 decreased in nitrate- and OM-rich summer.

To investigate potential changes in archaeal function along with season dynamics, functional profiles were predicted using Tax4Fun2. However, it is important to note that functional predictions through Tax4Fun2 cannot replace metagenomic or metatranscriptomic sequencing, as it does not represent the true abundance of functional genes. Unlike bacteria, there are relatively fewer archaeal whole genomes available in environments, which means that using Tax4Fun2 to infer functional genes of diverse archaeal lineages in environmental samples may have poor resolution. Therefore, the high number of ASVs unused in the Tax4Fun2 prediction was probably caused by the lack of reference genomes [67]. Our functional profiling showed that the relative abundance of genes involved in carbon, nitrogen, and sulfur cycles ranged from $0.019 \%$ to $0.062 \%$, which is close to the functional abundance of bacteria in mangrove sediments $(0.01 \sim 0.07 \%)$ [60] and microbial communities in sludge $(0.009 \sim 0.042 \%)$ [68]. The reason for the low abundance of the genes associated with element cycling is that most function predictions are performed in cellular biological processes (such as amino acid metabolism, carbohydrate metabolism, protein synthesis, etc.), in which energy metabolism genes occupy the majority of relative abundances. In addition, the scarcity of available archaeal genomes is also an important reason [67]. Further work is warranted to determine the accuracy of Tax4Fun2 compared to actual functionality, versus over or under-inflated predictions of pathways between genes. However, our results may provide a template for further metagenomic or metatranscriptomic studies on archaeal communities in seagrass sediments.

\section{Conclusions}

In this study, we examined seasonal effects on the diversity, composition, and functional potentials of the archaeal community in seagrass Z. japonica ecosystems. The highthroughput sequencing revealed that the overall archaeal communities in sediments were dominated by Bathyarchaeota, Thermoplasmatota, Asgardarchaeota, and Halobacterota, most of which showed a statistically significant difference in proportions and species richness among seasons, indicating strong seasonal variations in archaeal communities. Salinity and OM contents (TOC and TON) were major driving factors affecting ACS variations. Additionally, seasonality was also observed on the relative abundance of genes involved in cellulose and hemicellulose degradation and methane metabolism potentials, indicating that archaeal potential ecological functions shifted with seasonal changes. This work supplies a detailed database on the Z. japonica benthic archaeal communities, which can be used as a benchmark for future studies to measure shifts that are likely to occur due to anthropogenic interventions and climate changes in temperate seagrass meadows.

Supplementary Materials: The following are available online at https: / www.mdpi.com/article/ 10.3390/jmse9111304/s1, Figures S1-S3, Tables S1-S4. Figure S1: Geographical location of sampling sites for benthic archaeal communities of two Zostera japonica seagrass meadows (DY, Dongying; WH, Weihai), which were distributed on the coast of the Bohai Sea, north China; Figure S2: Rarefaction curves showing the numbers of archaeal observed richness at subsampling of 11,200 MiSeq reads obtained from 24 seagrass meadow sediment samples. Abbreviations: Sp, Spring; Su, Summer; $\mathrm{Au}$, Autumn; Wi, Winter; DY, Dongying; WH, Weihai; Figure S3: Principal component analysis (PCA) showing the seasonal differences of genes involved in carbon, methane, nitrogen, and sulfur cycles between two locations; Table S1: Environmental characteristics of the sediment (grain size, TOC, TON, nitrate, nitrite, and ammonia) and the overlaying water (temperature, salinity, $\mathrm{pH}$ ). The value represents mean \pm SE; Table S2: Summary of sequences obtained at processing steps; Table S3: Simple Mantel test for correlations between environmental factors and shifts in archaeal community structure based on Bray-Curtis and Jaccard distances; Table S4: List of selected genes associated with key energy metabolisms. 
Author Contributions: Conceptualization, P.L. and H.Z.; methodology, P.L.; software, P.L.; validation, P.L., Z.S., and Y.H.; formal analysis, P.L.; investigation, P.L.; resources, P.L.; data curation, P.L.; writing—original draft preparation, P.L.; writing—review and editing, P.L.; visualization, P.L.; supervision, X.H.; project administration, X.H.; funding acquisition, X.H. All authors have read and agreed to the published version of the manuscript.

Funding: This work was supported by the National Key Research and Development Program (2020YFD0901003), the National Natural Science Foundation of China (92051119, 42077305, and 32070112), the Special National Project on Investigation of Basic Resources of China (2019FY100700), the Key Research Project of Frontier Science of Chinese Academy of Sciences (QYZDB-SSW-DQC041), and the Taishan Scholar Project Special Funding (Tspd20210317).

Institutional Review Board Statement: Not applicable.

Informed Consent Statement: Not applicable.

Data Availability Statement: All raw data files of this study have been submitted to NCBI Sequence Read Archive under accession number PRJNA695132.

Acknowledgments: The authors greatly appreciated the anonymous reviewers for their careful work and thoughtful suggestions that improved this paper substantially.

Conflicts of Interest: The authors declare no conflict of interest.

\section{References}

1. Orth, R.J.; Carruthers, T.J.; Dennison, W.C.; Duarte, C.M.; Fourqurean, J.W.; Heck, K.L.; Hughes, A.R.; Kendrick, G.A.; Kenworthy, W.J.; Olyarnik, S.; et al. A Global Crisis for Seagrass Ecosystems. Bioscience 2006, 56, 987-996. [CrossRef]

2. Ugarelli, K.; Chakrabarti, S.; Laas, P.; Stingl, U. The Seagrass Holobiont and Its Microbiome. Microorganisms 2017, 5, 81. [CrossRef]

3. Mazarrasa, I.; Marbà, N.; Lovelock, C.E.; Serrano, O.; Lavery, P.S.; Fourqurean, J.W.; Kennedy, H.; Mateo, M.A.; Krause-Jensen, D.; Steven, A.D.L.; et al. Seagrass meadows as a globally significant carbonate reservoir. Biogeosciences 2015, 12, 4993-5003. [CrossRef]

4. Guannel, G.; Arkema, K.; Ruggiero, P.; Verutes, G. The Power of Three: Coral Reefs, Seagrasses and Mangroves Protect Coastal Regions and Increase Their Resilience. PLoS ONE 2016, 11, e0158094. [CrossRef] [PubMed]

5. Bertelli, C.M.; Unsworth, R.K. Protecting the hand that feeds us: Seagrass (Zostera marina) serves as commercial juvenile fish habitat. Mar. Pollut. Bull. 2014, 83, 425-429. [CrossRef]

6. Lilley, R.J.; Unsworth, R.K. Atlantic Cod (Gadus morhua) benefits from the availability of seagrass (Zostera marina) nursery habitat. Glob. Ecol. Conserv. 2014, 2, 367-377. [CrossRef]

7. Reynolds, P.L.; Duffy, E.; Knowlton, N. Seagrass and Seagrass Beds. Available online: https://ocean.si.edu/ocean-leaf/plantsalgae/seagrass-and-seagrass-beds (accessed on 22 March 2018).

8. Unsworth, R.K.; Nordlund, L.M.; Cullen-Unsworth, L.C. Seagrass meadows support global fisheries production. Conserv. Lett. 2018, 12, e12566. [CrossRef]

9. Fraser, M.W.; Statton, J.; Hovey, R.K.; Laverock, B.; Kendrick, G.A. Seagrass derived organic matter influences biogeochemistry, microbial communities, and seedling biomass partitioning in seagrass sediments. Plant Soil 2015, 400, 133-146. [CrossRef]

10. Kannan, R.R.R.; Arumugam, R.; Anantharaman, P.; Rengasamy, K.R. Antibacterial potential of three seagrasses against human pathogens. Asian Pac. J. Trop. Med. 2010, 3, 890-893. [CrossRef]

11. Lamb, J.B.; van de Water, J.A.J.M.; Bourne, D.G.; Altier, C.; Hein, M.Y.; Fiorenza, E.A.; Abu, N.; Jompa, J.; Harvell, C.D. Seagrass ecosystems reduce exposure to bacterial pathogens of humans, fishes, and invertebrates. Science 2017, 355, 731-733. [CrossRef]

12. Fahimipour, A.K.; Kardish, M.R.; Lang, J.M.; Green, J.L.; Eisen, J.A.; Stachowicz, J.J. Global-Scale Structure of the Eelgrass Microbiome. Appl. Environ. Microbiol. 2017, 83, e03391-16. [CrossRef]

13. Könneke, M.; Bernhard, A.E.; José, R.; Walker, C.B.; Waterbury, J.B.; Stahl, D.A. Isolation of an autotrophic ammonia-oxidizing marine archaeon. Nature 2005, 437, 543-546. [CrossRef] [PubMed]

14. Lloyd, K.G.; Schreiber, L.; Petersen, D.G.; Kjeldsen, K.U.; Lever, M.A.; Steen, A.; Stepanauskas, R.; Richter, M.; Kleindienst, S.; Lenk, S.; et al. Predominant archaea in marine sediments degrade detrital proteins. Nature 2013, 496, 215-218. [CrossRef]

15. Orphan, V.; House, C.H.; Hinrichs, K.-U.; McKeegan, K.D.; DeLong, E.F. Multiple archaeal groups mediate methane oxidation in anoxic cold seep sediments. Proc. Natl. Acad. Sci. USA 2002, 99, 7663-7668. [CrossRef] [PubMed]

16. Liu, J.; Zhu, S.; Liu, X.; Yao, P.; Ge, T.; Zhang, X.-H. Spatiotemporal dynamics of the archaeal community in coastal sediments: Assembly process and co-occurrence relationship. ISME J. 2020, 14, 1463-1478. [CrossRef]

17. Ettinger, C.L.; Voerman, S.E.; Lang, J.M.; Stachowicz, J.J.; Eisen, J.A. Microbial communities in sediment from Zostera marina patches, but not the Z. marina leaf or root microbiomes, vary in relation to distance from patch edge. PeerJ 2017, 5, e3246. [CrossRef] [PubMed]

18. Zheng, P.; Wang, C.; Zhang, X.; Gong, J. Community Structure and Abundance of Archaea in a Zostera marina Meadow: A Comparison between Seagrass-Colonized and Bare Sediment Sites. Archaea 2019, 2019, 5108012. [CrossRef] 
19. Zheng, S.; Wang, B.; Xu, G.; Liu, F. Effects of Organic Phosphorus on Methylotrophic Methanogenesis in Coastal Lagoon Sediments With Seagrass (Zostera marina) Colonization. Front. Microbiol. 2020, 11, 1770. [CrossRef]

20. Kalanetra, K.M.; Bano, N.; Hollibaugh, J.T. Ammonia-oxidizing Archaeain the Arctic Ocean and Antarctic coastal waters. Environ. Microbiol. 2009, 11, 2434-2445. [CrossRef]

21. Bhattacharyya, A.; Majumder, N.S.; Basak, P.; Mukherji, S.; Roy, D.; Nag, S.; Haldar, A.; Chattopadhyay, D.; Mitra, S.; Bhattacharyya, M.; et al. Diversity and Distribution of Archaea in the Mangrove Sediment of Sundarbans. Archaea 2015, 2015, 968582. [CrossRef]

22. Zhou, Z.; Meng, H.; Liu, Y.; Gu, J.-D.; Li, M. Stratified Bacterial and Archaeal Community in Mangrove and Intertidal Wetland Mudflats Revealed by High Throughput 16S rRNA Gene Sequencing. Front. Microbiol. 2017, 8, 2148. [CrossRef]

23. Herfort, L.; Schouten, S.; Abbas, B.; Veldhuis, M.J.W.; Coolen, M.J.L.; Wuchter, C.; Boon, J.P.; Herndl, G.J.; Sinninghe Damsté, J.S. Variations in spatial and temporal distribution of Archaea in the North Sea in relation to environmental variables. FEMS Microbiol. Ecol. 2007, 62, 242-257. [CrossRef]

24. Wong, A.H.L.; Visscher, P.; III, R.A.W.; Smith, D.-L.; Patterson, M.M.; Burns, B.P. Dynamics of archaea at fine spatial scales in Shark Bay mat microbiomes. Sci. Rep. 2017, 7, 46160. [CrossRef]

25. Smith, A.C.; Kostka, J.E.; Devereux, R.; Yates, D.F. Seasonal composition and activity of sulfate-reducing prokaryotic communities in seagrass bed sediments. Aquat. Microb. Ecol. 2004, 37, 183-195. [CrossRef]

26. Segovia, B.T.; Sanders-Smith, R.; Adamczyk, E.M.; Forbes, C.; Hessing-Lewis, M.; O'Connor, M.I.; Parfrey, L.W. Microeukaryotic Communities Associated With the Seagrass Zostera marina Are Spatially Structured. J. Eukaryot. Microbiol. 2021, 68, e12827. [CrossRef]

27. Seyler, L.; McGuinness, L.M.; Kerkhof, L.J. Crenarchaeal heterotrophy in salt marsh sediments. ISME J. 2014, 8, 1534-1543. [CrossRef] [PubMed]

28. Teske, A.; Sørensen, K.B. Uncultured archaea in deep marine subsurface sediments: Have we caught them all? ISME J. 2008, 2, 3-18. [CrossRef] [PubMed]

29. Evans, P.; Parks, D.H.; Chadwick, G.; Robbins, S.J.; Orphan, V.; Golding, S.D.; Tyson, G.W. Methane metabolism in the archaeal phylum Bathyarchaeota revealed by genome-centric metagenomics. Science 2015, 350, 434-438. [CrossRef]

30. He, Y.; Li, M.; Perumal, V.; Feng, X.; Fang, J.; Xie, J.; Sievert, S.; Wang, F. Genomic and enzymatic evidence for acetogenesis among multiple lineages of the archaeal phylum Bathyarchaeota widespread in marine sediments. Nat. Microbiol. 2016, 1, 16035. [CrossRef]

31. Lazar, C.S.; Baker, B.; Seitz, K.; Hyde, A.S.; Dick, G.J.; Hinrichs, K.-U.; Teske, A.P. Genomic evidence for distinct carbon substrate preferences and ecological niches of Bathyarchaeota in estuarine sediments. Environ. Microbiol. 2016, 18, 1200-1211. [CrossRef]

32. Sun, F.; Zhang, X.; Zhang, Q.; Liu, F.; Zhang, J.; Gong, J. Seagrass (Zostera marina) Colonization Promotes the Accumulation of Diazotrophic Bacteria and Alters the Relative Abundances of Specific Bacterial Lineages Involved in Benthic Carbon and Sulfur Cycling. Appl. Environ. Microbiol. 2015, 81, 6901-6914. [CrossRef] [PubMed]

33. Pires, A.; Cleary, D.; Almeida, A.; Cunha, A.; Dealtry, S.; Mendonça-Hagler, L.C.S.; Smalla, K.; Gomes, N.C.M. Denaturing Gradient Gel Electrophoresis and Barcoded Pyrosequencing Reveal Unprecedented Archaeal Diversity in Mangrove Sediment and Rhizosphere Samples. Appl. Environ. Microbiol. 2012, 78, 5520-5528. [CrossRef] [PubMed]

34. Callahan, B.J.; McMurdie, P.J.; Rosen, M.J.; Han, A.W.; Johnson, A.J.A.; Holmes, S.P. DADA2: High-resolution sample inference from Illumina amplicon data. Nat. Methods 2016, 13, 581-583. [CrossRef] [PubMed]

35. R Core Team. R: A language and environment for statistical computing. In Foundation for Statistical Computing; R Core Team: Vienna, Austria, 2018; Volume 3.6.3.

36. Martin, M. Cutadapt removes adapter sequences from high-throughput sequencing reads. EMBnet J. 2011, 17, 10-12. [CrossRef]

37. Murali, A.; Bhargava, A.; Wright, E.S. IDTAXA: A novel approach for accurate taxonomic classification of microbiome sequences. Microbiome 2018, 6, 140. [CrossRef]

38. McMurdie, P.J.; Holmes, S. phyloseq: An R Package for Reproducible Interactive Analysis and Graphics of Microbiome Census Data. PLoS ONE 2013, 8, e61217. [CrossRef]

39. Dixon, P. VEGAN, a package of R functions for community ecology. J. Veg. Sci. 2003, 14, 927-930. [CrossRef]

40. Wickham, H. ggplot2. Wiley Interdiscip. Rev. Comput. Stat. 2011, 3, 180-185. [CrossRef]

41. Segata, N.; Izard, J.; Waldron, L.; Gevers, D.; Miropolsky, L.; Garrett, W.S.; Huttenhower, C. Metagenomic biomarker discovery and explanation. Genome Biol. 2011, 12, R60. [CrossRef] [PubMed]

42. Wemheuer, F.; Taylor, J.A.; Daniel, R.; Johnston, E.; Meinicke, P.; Thomas, T.; Wemheuer, B. Tax4Fun2: Prediction of habitat-specific functional profiles and functional redundancy based on $16 \mathrm{~S}$ rRNA gene sequences. Environ. Microbiome 2020, 15, 1-12. [CrossRef]

43. Zhou, Z.; Pan, J.; Wang, F.; Gu, J.-D.; Li, M. Bathyarchaeota: Globally distributed metabolic generalists in anoxic environments. FEMS Microbiol. Rev. 2018, 42, 639-655. [CrossRef]

44. Katoh, K.; Standley, D.M. MAFFT Multiple Sequence Alignment Software Version 7: Improvements in Performance and Usability. Mol. Biol. Evol. 2013, 30, 772-780. [CrossRef]

45. Stamatakis, A. RAxML version 8: A tool for phylogenetic analysis and post-analysis of large phylogenies. Bioinformatics 2014, 30, 1312-1313. [CrossRef]

46. Darriba, D.; Taboada, G.L.; Doallo, R.; Posada, D. jModelTest 2: More models, new heuristics and parallel computing. Nat. Methods 2012, 9, 772. [CrossRef] 
47. Clarke, K.R. Non-parametric multivariate analyses of changes in community structure. Austral Ecol. 1993, 18, 117-143. [CrossRef]

48. Cifuentes, A.; Antón, J.; Benlloch, S.; Donnelly, A.; Herbert, R.A.; Rodríguez-Valera, F. Prokaryotic Diversity in Zostera noltii Colonized Marine Sediments. Appl. Environ. Microbiol. 2000, 66, 1715-1719. [CrossRef] [PubMed]

49. Sun, Y.; Song, Z.; Zhang, H.; Liu, P.; Hu, X. Seagrass vegetation affect the vertical organization of microbial communities in sediment. Mar. Environ. Res. 2020, 162, 105174. [CrossRef] [PubMed]

50. Lazar, C.S.; Biddle, J.; Meador, T.B.; Blair, N.; Hinrichs, K.-U.; Teske, A.P. Environmental controls on intragroup diversity of the uncultured benthic archaea of the miscellaneous Crenarchaeotal group lineage naturally enriched in anoxic sediments of the White Oak River estuary (North Carolina, USA). Environ. Microbiol. 2015, 17, 2228-2238. [CrossRef] [PubMed]

51. Zou, D.; Pan, J.; Liu, Z.; Zhang, C.; Liu, H.; Li, M. The Distribution of Bathyarchaeota in Surface Sediments of the Pearl River Estuary Along Salinity Gradient. Front. Microbiol. 2020, 11, 285. [CrossRef]

52. Yu, T.; Wu, W.; Liang, W.; Lever, M.A.; Hinrichs, K.-U.; Wang, F. Growth of sedimentaryBathyarchaeotaon lignin as an energy source. Proc. Natl. Acad. Sci. USA 2018, 115, 6022-6027. [CrossRef]

53. Davies, P.; Morvan, C.; Sire, O.; Baley, C. Structure and properties of fibres from sea-grass (Zostera marina). J. Mater. Sci. 2007, 42, 4850-4857. [CrossRef]

54. Kaal, J.; Serrano, O.; Nierop, K.G.; Schellekens, J.; Cortizas, A.M.; Mateo, M.-Á. Molecular composition of plant parts and sediment organic matter in a Mediterranean seagrass (Posidonia oceanica) mat. Aquat. Bot. 2016, 133, 50-61. [CrossRef]

55. Klap, V.; Hemminga, M.; Boon, J. Retention of lignin in seagrasses: Angiosperms that returned to the sea. Mar. Ecol. Prog. Ser. 2000, 194, 1-11. [CrossRef]

56. Meng, J.; Xu, J.; Qin, D.; He, Y.; Xiao, X.; Wang, F. Genetic and functional properties of uncultivated MCG archaea assessed by metagenome and gene expression analyses. ISME J. 2014, 8, 650-659. [CrossRef]

57. Pan, J.; Chen, Y.; Wang, Y.; Zhou, Z.; Li, M. Vertical Distribution of Bathyarchaeotal Communities in Mangrove Wetlands Suggests Distinct Niche Preference of Bathyarchaeota Subgroup 6. Microb. Ecol. 2019, 77, 417-428. [CrossRef]

58. Virta, L.; Soininen, J.; Norkko, A. Stable Seasonal and Annual Alpha Diversity of Benthic Diatom Communities Despite Changing Community Composition. Front. Mar. Sci. 2020, 7, 88. [CrossRef]

59. Azam, F.; Malfatti, F. Microbial structuring of marine ecosystems. Nat. Rev. Microbiol. 2007, 5, 782-791. [CrossRef] [PubMed]

60. Zhu, P.; Wang, Y.; Shi, T.; Zhang, X.; Huang, G.; Gong, J. Intertidal zonation affects diversity and functional potentials of bacteria in surface sediments: A case study of the Golden Bay mangrove, China. Appl. Soil Ecol. 2018, 130, 159-168. [CrossRef]

61. Kawashima, T.; Amano, N.; Koike, H.; Makino, S.-I.; Higuchi, S.; Kawashima-Ohya, Y.; Watanabe, K.; Yamazaki, M.; Kanehori, K.; Kawamoto, T.; et al. Archaeal adaptation to higher temperatures revealed by genomic sequence of Thermoplasma volcanium. Proc. Natl. Acad. Sci. USA 2000, 97, 14257-14262. [CrossRef] [PubMed]

62. Walsh, D.A.; Papke, R.; Doolittle, W.F. Archaeal diversity along a soil salinity gradient prone to disturbance. Environ. Microbiol. 2005, 7, 1655-1666. [CrossRef]

63. Valenzuela, E.I.; Prieto-Davó, A.; López-Lozano, N.E.; Eligio, A.H.; Vega-Alvarado, L.; Juárez, K.; García-González, A.S.; López, M.G.; Cervantes, F.J. Anaerobic Methane Oxidation Driven by Microbial Reduction of Natural Organic Matter in a Tropical Wetland. Appl. Environ. Microbiol. 2017, 83, e00645-17. [CrossRef] [PubMed]

64. Zhang, G.; Jiang, N.; Liu, X.; Dong, X. Methanogenesis from Methanol at Low Temperatures by a Novel Psychrophilic Methanogen, "Methanolobus psychrophilus" sp. nov., Prevalent in Zoige Wetland of the Tibetan Plateau. Appl. Environ. Microbiol. 2008, 74, 6114-6120. [CrossRef] [PubMed]

65. Dukunde, A.; Schneider, D.; Schmidt, M.; Veldkamp, E.; Daniel, R. Tree Species Shape Soil Bacterial Community Structure and Function in Temperate Deciduous Forests. Front. Microbiol. 2019, 10, 1519. [CrossRef] [PubMed]

66. Fillol, M.; Sànchez-Melsió, A.; Gich, F.; Borrego, C.M. Diversity of Miscellaneous Crenarchaeotic Group archaea in freshwater karstic lakes and their segregation between planktonic and sediment habitats. FEMS Microbiol. Ecol. 2015, 91, fiv020. [CrossRef]

67. Wemheuer, F.; Von Hoyningen-Huene, A.J.E.; Pohlner, M.; Degenhardt, J.; Engelen, B.; Daniel, R.; Wemheuer, B. Primary Production in the Water Column as Major Structuring Element of the Biogeographical Distribution and Function of Archaea in Deep-Sea Sediments of the Central Pacific Ocean. Archaea 2019, 2019, 3717239. [CrossRef] [PubMed]

68. Song, L.; Song, Y.; Li, D.; Liu, R.; Niu, Q. The auto fluorescence characteristics, specific activity, and microbial community structure in batch tests of mono-chicken manure digestion. Waste Manag. 2019, 83, 57-67. [CrossRef] 